\title{
Ultrastructure of the epithelial cells and oleo-gumresin secretion in Boswellia serrata (Burseraceae)
}

\begin{abstract}
The ultrastructure of epithelial cells of oleo-gumresin ducts in Boswellia serrata, the source of Indian olibanum, is described. Oleo-gumresin ducts are present in primary and secondary phloem. The duct lumen forms an enlarged apoplastic space surrounded by epithelial cells. The epithelial cells are rich in dictyosomes, lipid bodies, mitochondria with dilated cristae, multivesicular bodies, osmiophilic materials, plastids and vesicles. Plastids have poorly developed internal membranes. Dictyosomes and plastids are possible sites of resin synthesis. The gum component of the exudate is formed in dictyosomes and from the outer layers of the inner tangential wall (wall facing the duct lumen). This wall is replenished from inside by the activity of dictyosomes. The secretory materials are transported to the apoplast by granulocrine and eccrine secretion. They migrate through the loose microfibrils of the inner tangential wall into the duct lumen. Rarely, epithelial cells of young ducts have rudimentary plasmodesmata on the inner tangential wall which may be channels for passage of secretory materials into the duct lumen.
\end{abstract}

Keyword: Boswellia serrata; Granulocrine and eccrine secretion; Indian olibanum; Medicinal plant; Oleo-gumresin; Salai guggal; Ultrastructure 